\title{
VIBRATION ANALYSIS OF SINGLE LAP JOINT OF COMPOSITE PLATES BASED ON VARIATIONS OF PLATE THICKNESS AND OVERLAP LENGTH
}

\author{
BOBBY YUSUF HAKA* \\ Department of Materials and Metallurgical Engineering, \\ Institut Teknologi Sepuluh Nopember, \\ Kampus ITS Keputih Sukolilo, 60111, Surabaya, East Java, Indonesia \\ hakabobby@gmail.com \\ MAS IRFAN PURBAWANTO HIDAYAT \\ Department of Materials and Metallurgical Engineering, \\ Institut Teknologi Sepuluh Nopember, \\ Kampus ITS Keputih Sukolilo, 60111, Surabaya, East Java, Indonesia \\ irfan@mat-eng.its.ac.id \\ WIDYASTUTI \\ Department of Materials and Metallurgical Engineering, \\ Institut Teknologi Sepuluh Nopember, \\ Kampus ITS Keputih Sukolilo, 60111, Surabaya, East Java, Indonesia \\ wiwid@mat-eng.its.ac.id \\ * Corresponding author
}

Received 10 January 2021; Published 31 December 2021

\begin{abstract}
Adhesive bonding is widely used for joining metals or composites in marine, aircraft, automotive, railroad, and civil construction industries. Adhesive single lap joint offers many advantages in terms of time and cost savings, has good damping characteristics, and provides high joint strength compared to another conventional joint. In this study, an analysis of free vibration of composite single lap joint has been carried out using by modal analysis solver i.e. ANSYS. Optimization study is then carried out to obtain the optimal design for vibration resistance. The simulation results of the natural frequency for each variation of joint thickness and overlap length are obtained through this study. The results show that increasing thickness and overlap length will increase the value of natural frequency as well, thus giving better vibration resistance. It is found that the optimum thickness and overlap length are $2.54 \mathrm{~mm}$ and $70 \mathrm{~mm}$, respectively. The results point out the importance of joint thickness and overlap length for the vibration resistance of single lap joint of composite plates.
\end{abstract}

Keywords: adhesive bonding; single lap joint; joint thickness; overlap length; joint vibration resistance.

\section{Introduction}

Ideally, a component design will be designed without joints because it can be the weakest point source under the influence of structural loads. However, limitations in component size due to manufacturing, inspection, accessibility, transportation and assembly processes necessitate the joint design in the component structures (Das and Pradhan, 2010). Although the joint technique using bolts or rivets has long been used in the construction and manufacturing industry due to its simple use, in fact the joint using bolts or rivets often suffer from damage around the hole when receiving high impact and load due to stress concentration factor. Besides, the use of mechanical fasteners can also increase the structural weight of the material.

The use of adhesive is now an alternative in the joint of composite or even metal materials because it is much lighter and spreading stress more uniformly through joints. However, the adhesion and deformation mechanism of the adhesive joint become complicated under static and dynamic loading. In its application, harmonic and impact loads cause the joint to experience damped harmonic vibrations that can affect the strength of the joint and its lifetime. The dynamic response of adhesive joints to harmonic loads needs to be studied to achieve a long 


\section{Haka et. al.}

service life. This can be investigated through a free vibration analysis by knowing natural frequencies and mode shapes of the adhesive joint so that the strength and lifetime of the adhesive joint can be increased based on the most critical vibrational modes.

In this study, the focus is on analyzing the design of single lap joint of composites with adhesive. The investigation is on geometric parameters of the plate thickness $(t)$ and overlap length $(c)$ in such a way that an optimal design can be obtained for the single lap joint of composites.

\section{Composite Plate and Lap Joint}

A composite material is a combination of two or more materials with the aim of obtaining new materials that have superior properties by combining the mechanical properties of the constituent materials. The advantage of composite materials is high strength and stiffness with light density so can reduce the structural weight of the material. Moreover, composite also has good fatigue and corrosion resistance and easy manufacturing so that it can be formed according to product design (Jones, 1999; Campbell, 2010). Epoxy is the most used matrix for composites with high performance because it has the best combination in terms of strength, adhesion, low shrinkage, and flexibility in processing (Campbell, 2010). Epoxy is a cyclic ether compound characterized by a triangular ring or an oxirane ring, as shown in Fig 1.

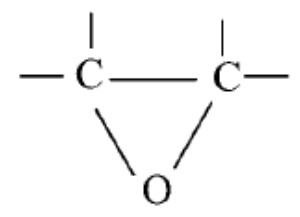

Fig. 1. Chemical structure of epoxy.

Furthermore, graphite and carbon fibre are the most widely used fibres for making composite materials because they can be produced with a variety of properties. In their application, they show superior tensile and compressive strength, have excellent fatigue resistance and are not easy to corrode. Graphite fibre, consisting of carbon atoms arranged lamellar in hexagonal layers shown in Fig. 2, can be made from polyacrylonitrile (PAN), rayon, and precursor pitch (Campbell, 2010).

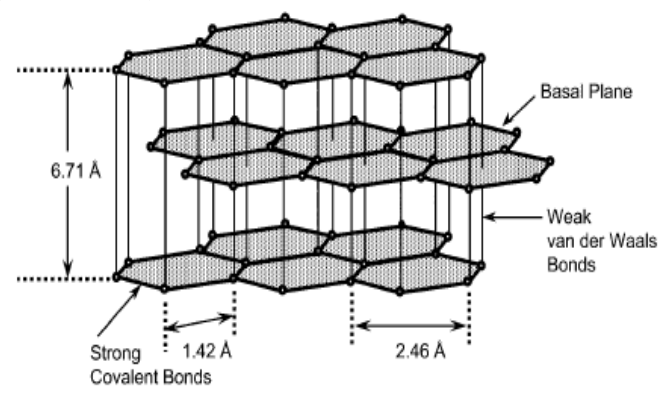

Fig. 2. Graphite crystal structure.

\subsection{Micromechanics of Composite}

Composite micromechanics can be used to predict the properties of a composite by using rule of mixtures (Apalak and Yildirim, 2007), as given by the following equations:

$$
\begin{aligned}
& E_{1}=E_{f} V_{f}+E_{m} V_{m} \\
& E_{2}=\frac{E_{f} E_{m}}{E_{f} V_{m}+E_{m} V_{f}}
\end{aligned}
$$


Haka et. al.

$$
\begin{gathered}
G_{12}=\frac{G_{f} G_{m}}{G_{f} V_{m}+G_{m} V_{f}} \\
v_{12}=v_{f} V_{f}+v_{m} V_{m} \\
\rho=\rho_{f} V_{f}+\rho_{m} V_{m} \\
\frac{v_{21}}{E_{2}}=\frac{v_{12}}{E_{1}}
\end{gathered}
$$

where: $E_{1}$ is the longitudinal elastic modulus, $E_{2}$ is the transverse elastic modulus, $G_{12}$ is the shear modulus, $v_{12}$, $v_{21}$ are the Poisson ratios (major and minor), and $\rho$ is the density.

\subsection{Adhesive Joint}

Adhesive joint is a joint technique to eliminate losses from conventional joints. In its application, the adhesive is used to combine two separate parts and placed between the adherends (Campbell, 2010).

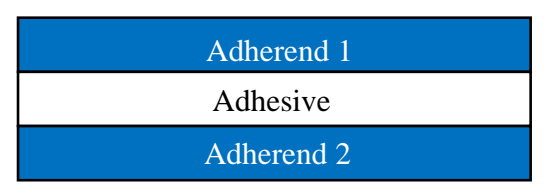

Fig. 3. A schematic of adhesive joint.

Fig. 3 shows the adhesive joint schematic. The advantage of adhesive joints is that they can combine two materials with different geometries, sizes and compositions as the adhesive (epoxy resin) will harden and rigid with high adhesion after curing. Moreover, it can eliminate the appearance of corrosion due to galvanic potential differences. The adhesive bond also gives high flexibility to the product design by the aesthetic value. Furthermore, adhesive bonding can reduce noise and vibration and prolong service life because it has resistance to fatigue and high impact.

\subsection{Dynamics Equation of Motion}

The dynamics equation of motion of a structure can be derived by using the Lagrange and Hamilton's principle (Rao, 1989), given as:

$$
[M]\{\ddot{Q}\}+[K]\{Q\}=0
$$

where: $[\mathrm{M}]$ is the matrix of mass, $[K]$ is the stiffness matrix, $\{Q\}$ and $\{\ddot{Q}\}$ are the nodal displacement and acceleration vectors, respectively.

\subsection{Shear Stress of Single Lap Joint}

Commonly, a lap shear stress test is carried out to evaluate and assess the strength of adhesive joint under the shear influence. This test is one of the most frequently used tests as it is inexpensive, easy to make and simple to do (Petrie, 2000). The lap shear stress is given by:

$$
\tau=\frac{P}{b l}
$$

where: $P$ is the given load, $b$ is the joint width, $l$ is the overlap length and $\tau$ is the adhesive shear stress.

If the adherends are rigid, the stress distribution will be uniform, whereas if the adherends are elastic then the stress distribution will be non-uniform, as shown in Figs, 4(a) and (b). In the non-uniform case of stress 
Haka et. al.

distribution, the stress value at the joint ends will be higher and gradually decreases at the mid-overlap as illustrated in Fig. 4.

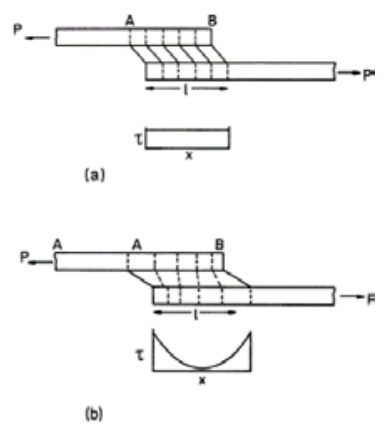

Fig. 4. Shear loading scheme on a single lap joint of composite plates.

\section{Materials and Geometrical Model}

The composite material used is unidirectional laminate composite (IM-6/3501-6) made of IM-6 (graphite fiber, Hexcel) and 3501-6 (epoxy, Hercules) with a lamina thickness of $0.1335 \mathrm{~mm}$ and the direction of unidirectional fibers $\left[0^{\circ}\right]$ with $\mathrm{V}_{\mathrm{f}}=0.635$ (Apalak and Yildirim, 2007). The mechanical properties of graphite fiber, epoxy resin and lamina are shown in Table 1.

Table 1. Mechanical properties of graphite fiber, epoxy resin and lamina

\begin{tabular}{cccc}
\hline \hline Property & Fiber & Epoxy Resin & Lamina \\
\hline$\rho(\mathrm{kg} / \mathrm{m} 3)$ & 1743.834 & 1264.972 & 1552.289 \\
$E_{11}(\mathrm{GPa})$ & 259.105 & 4.344 & 157.218 \\
$E_{22}=E_{33}(\mathrm{GPa})$ & 13.927 & 4.344 & 9.309 \\
$G_{12}=G_{13}(\mathrm{GPa})$ & 50.952 & 1.597 & 5.723 \\
$G_{23}(\mathrm{GPa})$ & 8.274 & 1.597 & 3.475 \\
$v_{12} v_{13}$ & 0.26 & 0.36 & 0.3 \\
$v_{23}$ & 0.33 & 0.36 & 0.34 \\
\hline \hline
\end{tabular}

In this study, the adhesive thickness is set to be $0.2 \mathrm{~mm}$ and the length $\mathrm{L}$ of the composite plates is taken as $250 \mathrm{~mm}$., while the parameters of single lap joint varied in the simulation can be seen in Table 2 .

Table 2. Variations of plate thickness and overlap length

\begin{tabular}{ccc}
\hline \hline & Plate thickness $t(\mathrm{~mm})$ & Overlap length $c(\mathrm{~mm})$ \\
\hline Model 1 & 2 & 55 \\
Model 2 & 2 & 60 \\
Model 3 & 2 & 65 \\
Model 4 & 2.27 & 55 \\
Model 5 & 2.27 & 60 \\
Model 6 & 2.27 & 65 \\
Model 7 & 2.54 & 55 \\
Model 8 & 2.54 & 60 \\
Model 9 & 2.54 & 65 \\
\hline \hline
\end{tabular}


Haka et. al.

\section{Results and Discussion}

\subsection{Effect of Plate Thickness and Overlap Length on Vibration Resistance of Single Lap Joint}

Fig. 7 shows that at the same thickness value, the magnitude of natural frequency appears to increase as the overlap length increases. The increase of the natural frequency is more evident in particular at higher modes of vibration. Likewise, at the same overlap length value, the magnitude of natural frequency increases as the thickness increases, as shown in Fig. 8. The increase in the natural frequency means better vibration resistance i.e. the joint structure is stiffer, thus tougher (He, 2012; Zhang et al., 2017; Kadioglu et al., 2019). In addition, as most of the components often experience complex stress cycles with varying amplitudes throughout their working life (Hidayat and Yusoff, 2009; Hidayat, 2015), therefore it is also expected that the tougher joint structure will produce better fatigue resistance as well, thus producing longer lifetime. Those simulation results are also consistent with the study by Apalak and Yildirim (2007). For more clarity of comparison, Table 3 shows simulation results of the first natural frequencies of the joint structure with as the values of plate thickness and overlap length are varied.

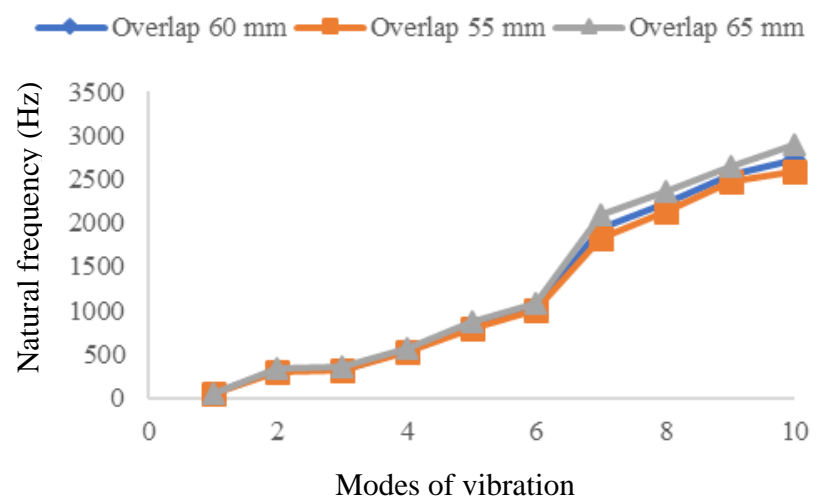

(a)

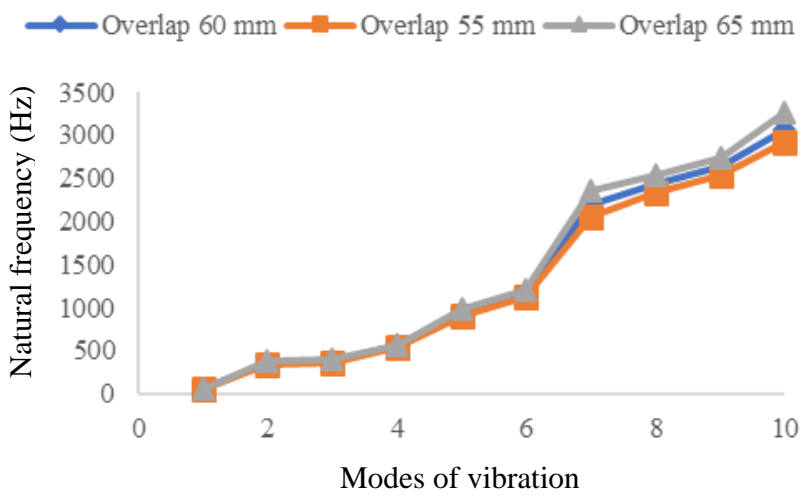

(b)

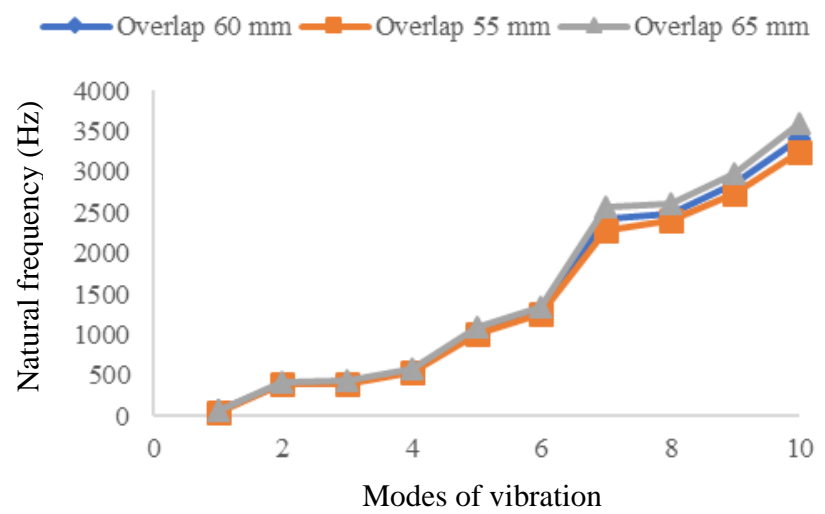

(C)

Fig. 7. Natural frequencies of the first ten vibration modes of the joint structure with the variation of overlap length for plate thickness: (a) $2 \mathrm{~mm}$, (b) $2.27 \mathrm{~mm}$, and (c) $2.54 \mathrm{~mm}$. 
Haka et. al.

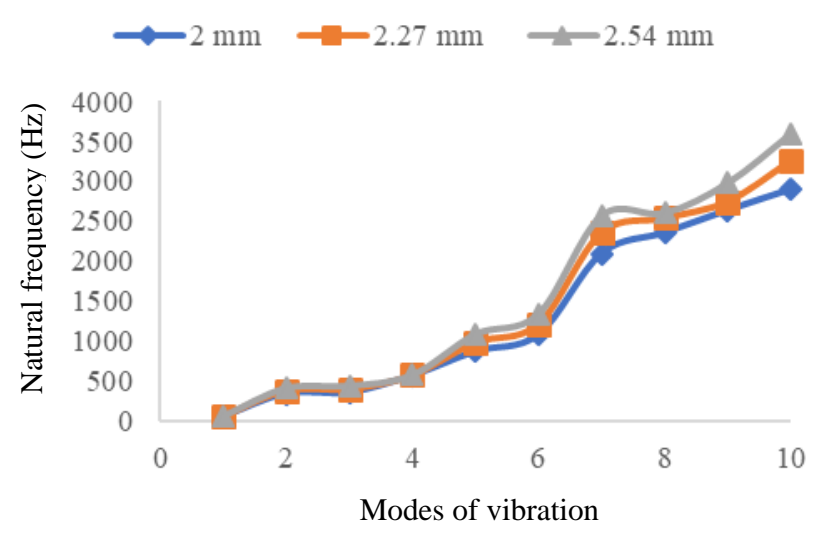

(a)

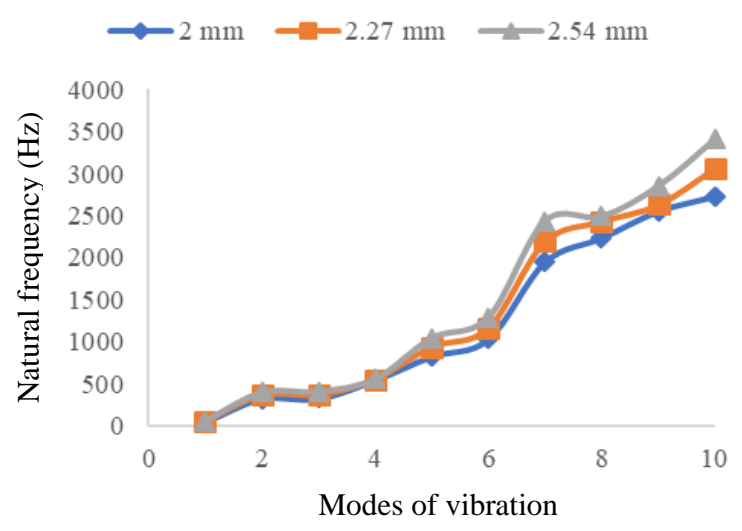

(b)

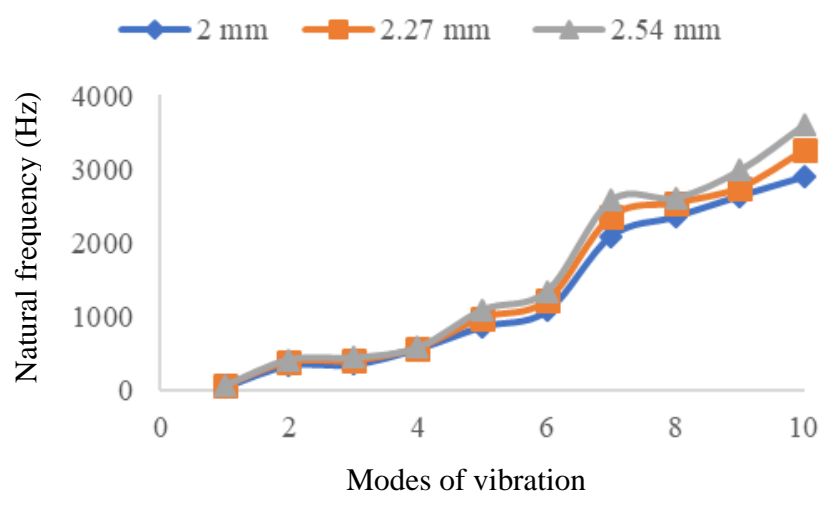

(c)

Fig. 8. Natural frequencies of the first ten vibration modes of the joint structure with the variation of plate thickness for overlap length: (a) $55 \mathrm{~mm}$, (b) $60 \mathrm{~mm}$, and (c) $65 \mathrm{~mm}$.

Table 3. Simulation results of the first natural frequencies (mode 1) of the joint structure

\begin{tabular}{cccc}
\hline \hline Dimension & \multicolumn{3}{c}{ First natural frequency $(\mathrm{Hz})$} \\
\hline Plate thickness & $55 \mathrm{~mm}$ & Overlap length & $65 \mathrm{~mm}$ \\
\cline { 2 - 4 } & 45.49 & $60 \mathrm{~mm}$ & 49.00 \\
\hline $2 \mathrm{~mm}$ & 51.61 & 47.18 & 55.58 \\
\hline $2.27 \mathrm{~mm}$ & 57.74 & 53.53 & 62.15 \\
\hline
\end{tabular}

Furthermore, the simulation results of 10 first mode shapes of the joint structure by using modal analysis with ANSYS software are depicted in Fig. 9 for clarity of presentation. 


\section{Haka et. al.}

Fig. 9. Simulation results of 10 mode shapes of the joint structure.
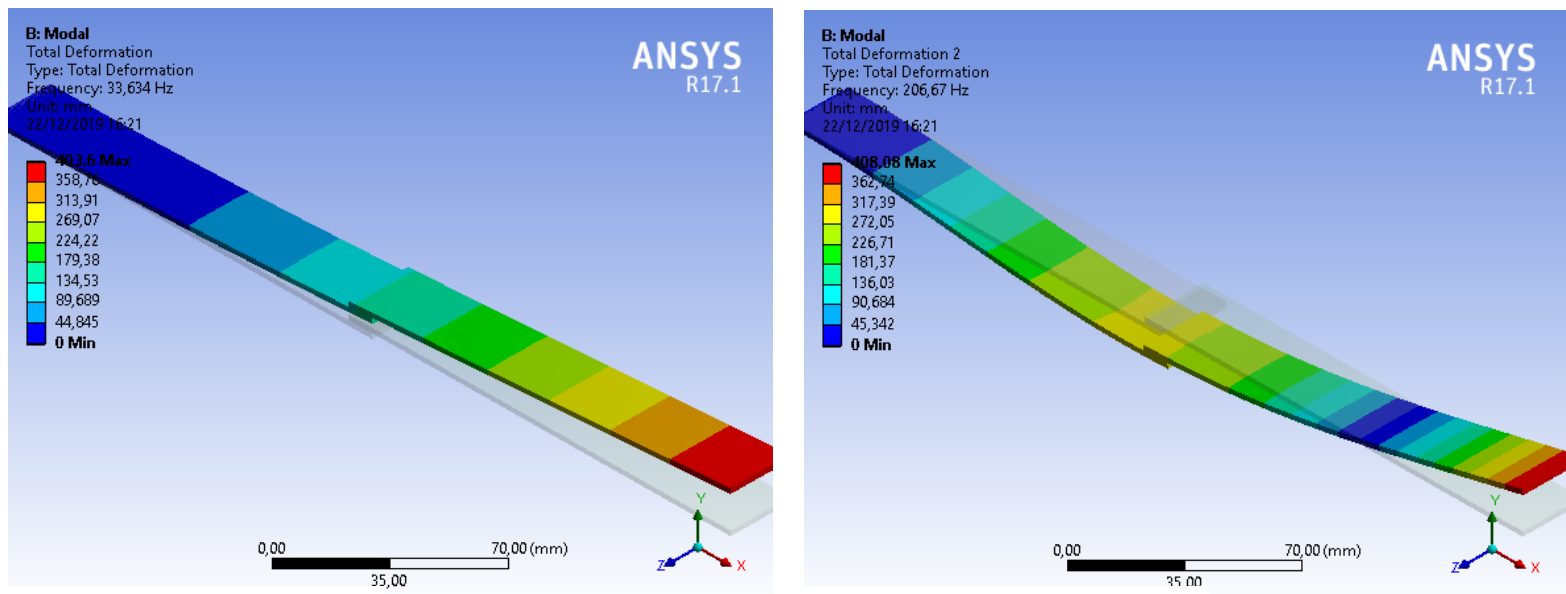

Mode 1

Mode 2
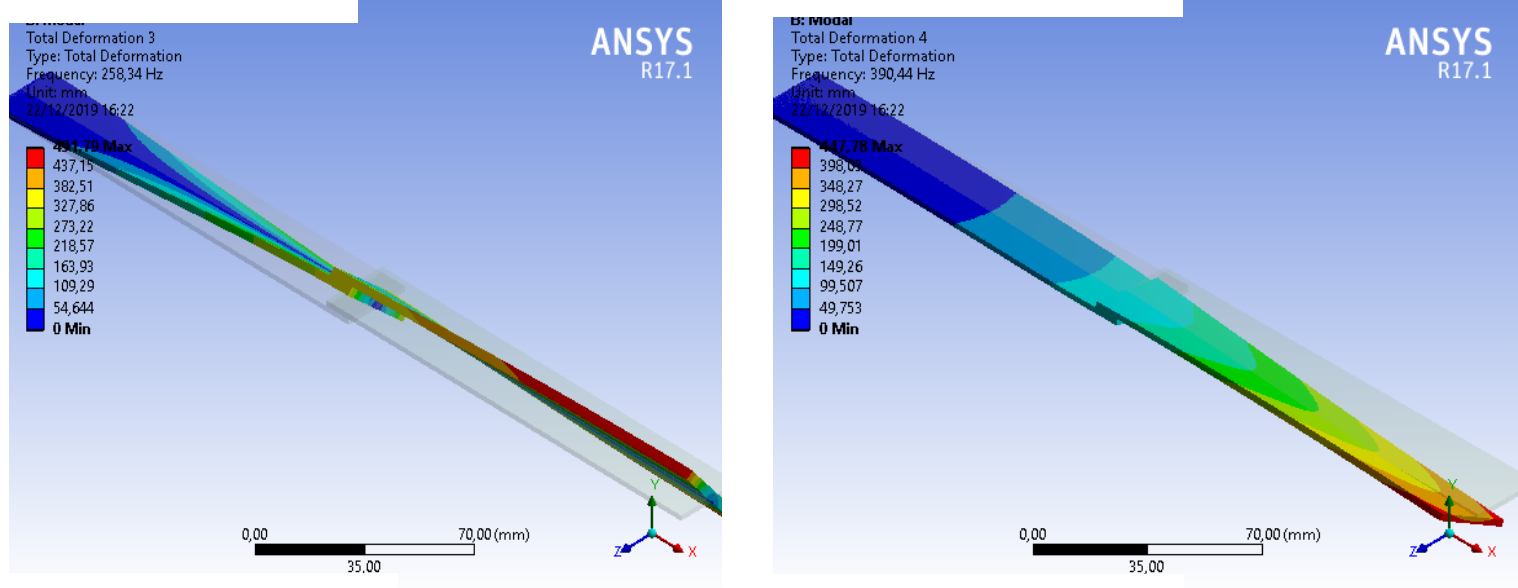

\section{Mode 3}

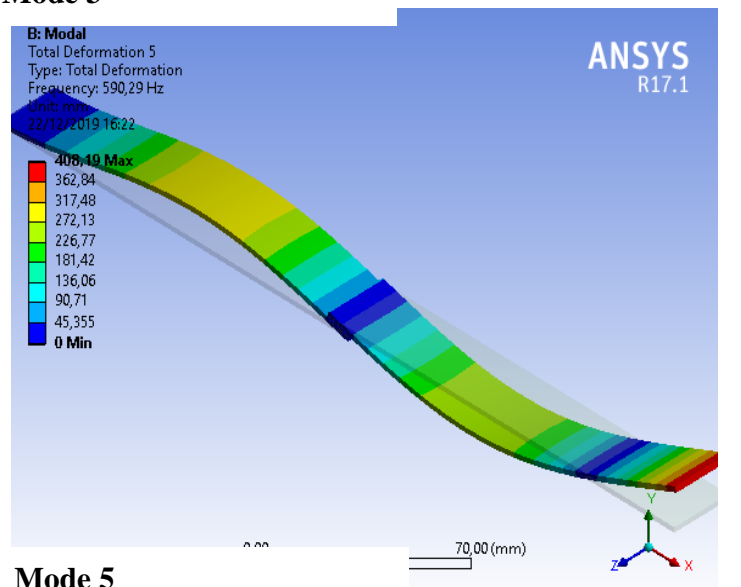

Mode 4

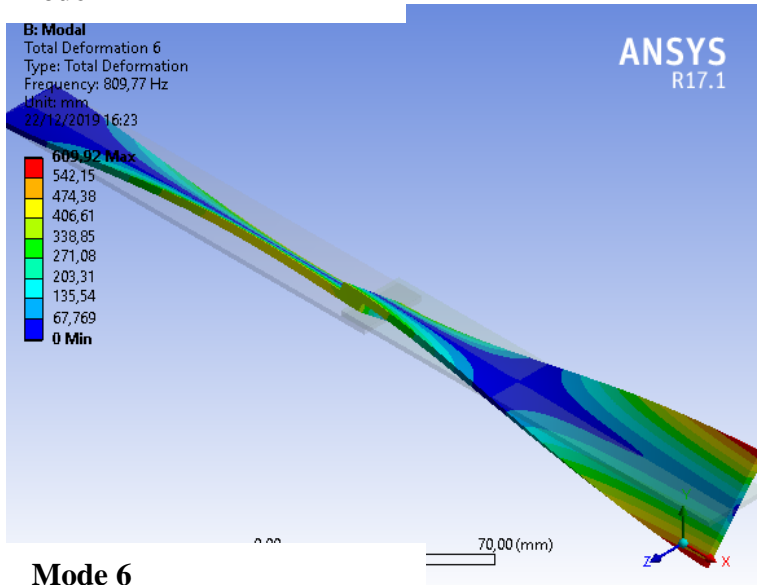


Haka et. al.

Fig. 9. Simulation results of 10 mode shapes of the joint structure (continued).
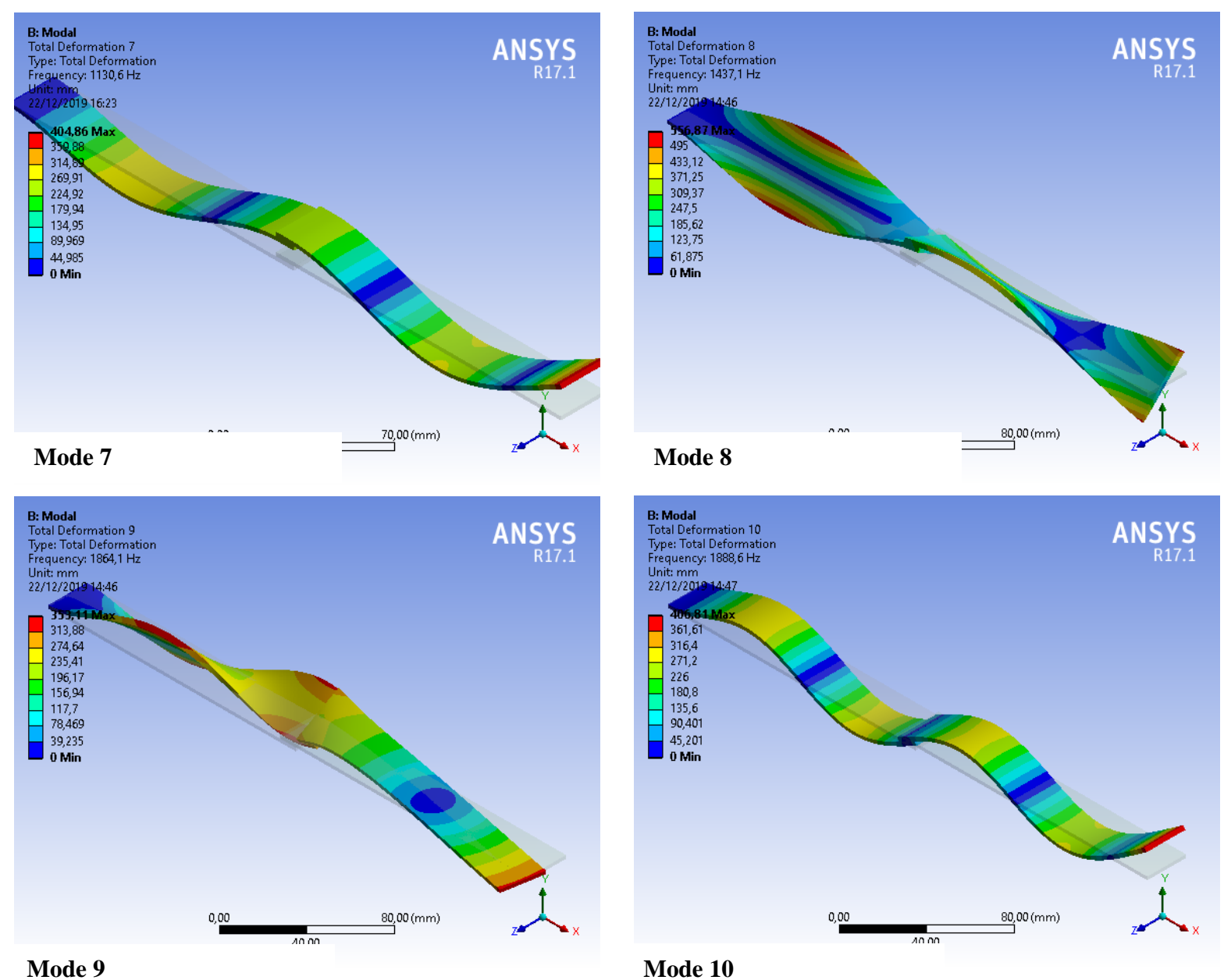

Mode 9

Mode 10

It is important to note that the increase in overlap length will make the joint area increases as well. Besides giving a smoother transition of geometrical change of joint, this will result in a more uniform stress distribution over the joint area, thus yielding less concentration factor. As a result, increasing the overlap length can increase the joint strength in term of vibration resistance as well. However, it is also important to point out the limit value for the overlap length as the continuous increase of overlap length is not necessarily followed by an increase in the bond/joint load capacity as the joint structure will be more pronounced to anti-plane bending. In addition, the failure propagation due to delamination will be more pronounced as well (Karachalios et al., 2013). Investigation on the strength and vibration resistance of single lap joint of composite plates by using other numerical methods (Hidayat et al., 2016; Hidayat et al., 2020) will be also interesting as subjects of further research study.

\section{Conclusions}

Vibration analysis of single lap joint of composite plates has been presented in this study. Increasing overlap length and plate thickness of the joint structure will produce higher natural frequency. From the present study, single lap joint with an overlap length of $65 \mathrm{~mm}$ and plate thickness of $2.54 \mathrm{~mm}$ was the optimum geometry design for the joint structure in term of vibration resistance. 
Haka et. al.

\section{Acknowledgments}

The present authors would like to thank the Laboratory of Materials Innovation, Department of Materials and Metallurgical Engineering ITS Surabaya for supporting this research work.

\section{References}

Apalak, M.K. and Yildirim, M. 2007. "Free Vibration Analysis and Optimal Design of a Cantilevered Adhesively Bonded Composite Tubular Single Lap Joins”. Polymers \& Polymer Composites, 489-490.

Campbell, F.C. 2010. Structural Composite Materials. USA: ASM International.

Das, R.R. and Pradhan, B. 2010. “Adhesion failure analyses of bonded tubular single lap joints in laminated fibre reinforced plastic composites”. International Journal of Adhesion and Adhesives, 5:425-438.

He, X. (2012). 'Numerical and experimental investigations of the dynamic response of bonded beams with a single-lap joint'. International Journal of Adhesion and Adhesives, 37:79-85.

Hidayat, M.I.P. (2015). System Identification Technique and Neural Networks for Material Lifetime Assessment Application. In Q. Zhu \& A.T. Azar (Eds.), Complex System Modelling and Control Through Intelligent Soft Computations, Studies in Fuzziness and Soft Computing 319 (pp. 773-806). Switzerland: Springer International Publishing.

Hidayat, M.I.P., and Yusoff, P.S.M.M. (2009). Optimizing Neural Network Prediction of Composite Fatigue Life Under Variable Amplitude Loading Using Bayesian Regularization. In S. M. Sapuan \& I.M. Mujtaba (Eds.), Composite Materials Technology: Neural Network Applications (pp. 221-249). New York, USA: CRC Press.

Hidayat, M.I.P., Ariwahjoedi, B. and Parman, S. (2016), "B-spline collocation method for boundary value problems in complex domains", Int. J. Computing Science and Mathematics, Vol. 7(2), pp. 110-125.

Hidayat, M.I.P., Widyastuti and Fajarin, R. (2020), "A meshless generalized finite difference method for 2D elasticity problems", Engineering Analysis with Boundary Elements, Vol. 117, pp. 89-103.

Jones, R. M. (1999). Mechanics of Composite Materials. New York: Taylor and Francis Group.

Kadioglu, F., Demiral, M. and El Zaroug, M. 2019. "Effects of overlap length on the strength of bolted, bonded and hybrid single lap joints with different adherend materials and thicknesses”. Journal of Adhesion Science and Technology 9, 4:234-235.

Karachalios, E.F., Adams, R.D. and da Silva L.F.M. (2013). 'The behaviour of single lap joints under bending loading’. Journal of Adhesion Science and Technology, 27(16): 1811-1827.

Petrie, E.M. 2000. Handbook of Adhesives and Sealants. USA: McGraw-Hill.

Rao, S. 1989. The Finite Element Method. Oxford: Pergamon Press.

Zhang, J., He, X., Liu, W. and Wang., R. 2017. "Numerical Studies of Adherend Thickness Influence on the Response of Single Lap Joint under Longitudinal Load”. Advances in Engineering Research, 113:664-668. 